\title{
Gestão do conhecimento em indústria de alta tecnologia
}

\author{
Isabel Cristina dos Santos UNITAU \\ João Amato Neto EPUSP
}

\section{RESUMO}

O objetivo deste trabalho é descrever o processo de Gestão do Conhecimento na indústria aeronáutica nacional. O problema central investigado refere-se a como uma indústria de alta tecnologia, que produz sob encomenda, com um longo leadtime, gera conhecimento, dado o rápido deslocamento das fronteiras tecnológicas. A metodologia foi pautada em pesquisa documental, na aplicação de questionários, para um grupo, e entrevistas não-estruturadas, para outro grupo, escolhidos por amostra não-probabilística. Para a análise, utilizou-se um estudo de caso. Observou-se que as inovações estão limitadas aos conteúdos conhecidos das ciências e suas aplicações, e são fortemente orientadas à melhoria contínua. A indústria é o principal agente das mudanças do setor, apoiada pelo comprometimento da organização humana que promove a adaptação da empresa aos novos requisitos e tendências do ambiente tecnológico e competitivo. Para tanto, a indústria prioriza o desenvolvimento das competências técnicas, mercadológicas e empresariais, por meio da capacitação contínua.

\section{PALAVRAS-CHAVE}

Gestão do conhecimento, ambiente tecnológico, ambiente de negócios, organização humana.

\section{Knowledge management in a high technology industry}

\begin{abstract}
This paper aims to contribute to Knowledge Management debate for High Technology Industry, in Brazil. The investigated problem refers to "how can an industry, that manufactures under the customers orders, in a long-term commitment and lead time, generate the state of art knowledge, considering the accelerated moves of the technology boundaries? The methodology techniques were primarily defined in terms of a qualitative approach, based on a historic documentation analysis regarding a single case study. Data collecting was supported by questionnaires, filled by a technical group, and also some non-structured interviews made to another group. At the end of the investigative process some conclusions have been pointed out such as: innovative aspects of Hi-Tech are limited by the available knowledge in sciences related and also its appliances; Hi-tech enterprises generates themselves innovation through $R \& D$, aiming to fulfill the lack of a governmental investments program. To implement adaptations required by the new technological and competitive order, a cluster of human competencies are demanded. So, they can be developed through educational process which includes people and leadership development.
\end{abstract}

\section{KEY WORDS}

Knowledge management, technological environment, business environment, human organization. 


\section{INTRODUÇÃO}

A literatura tem destacado como um dos maiores desafios organizacionais das próximas décadas a capacidade das organizações em gerarem vantagens competitivas duradouras. O desafio é particularmente mais intenso para as indústrias que dependam de alta tecnologia, de longo ciclo de maturação e de alta complexidade, dada a gama de componentes e aplicações possíveis resultantes da tecnologia desenvolvida. Neste sentido, o conhecimento e a capacidade de inovação são fatores-chave de sucesso e habilitadores para a melhor compreensão e atendimento de necessidades dos clientes por produtos e serviços, diferenciação de produtos e processos entre as empresas do mesmo setor.

Prahalad (1998) havia identificado oito tendências no cenário competitivo mundial, as quais afetariam o acervo de competências e conhecimentos das empresas de alta competição. São elas: a) o efeito globalização, que provocaria o abandono da economia planejada para a economia de mercado; b) desregulamentação e privatizações como uma tendência mundial em setores de alta demanda, resultando em aumento das fusões e aquisições; c) volatilidade do processo produtivo associado à imprevisibilidade da demanda, gerando uma necessidade imperiosa de criar fábricas flexíveis, capazes de atender várias unidades de negócio; d) convergência, responsável pela integração de várias funções, antes independentes, em um mesmo produto; e) fronteiras tênues entre os setores em razão da convergência, acarretando que as empresas produtivas venham a ser as novas concorrentes do setor de serviços financeiros, por exemplo; f) aumento da colaboração entre concorrentes para definição de padrões para lançamento de produtos tecnológicos com os quais concorrerão entre si; g) fim da intermediação, ou seja, a distância entre produtor e o usuário final está diminuindo; e h) consciência ecológica, o que forçará a adoção de um modelo baseado em obrigações sociais em relação ao ambiente e qualidade de vida. Tais tendências, algumas das quais amplamente reconhecidas como prioritárias, como a questão da preservação do ambiente e qualidade de vida, encaminharão as organizações a um elevado nível de diversidade no processo decisório, o que as obrigará à criação de debates especializados para a solução de problemas.

A mudança no ambiente competitivo foi avaliada por Hitt, Ireland e Hoskisson (2002), que identificaram as seguintes categorias de tendência:

- Crescente taxa de mudança e de disseminação tecnológica: o termo inovação tem sido utilizado para descrever a velocidade com a qual as novas tecnologias baseadas em uma grande quantidade de informações e conhecimento substituem as tecnologias em uso.
- Caracterização do momento atual como a Era da Informação: os meios de difusão de informação, em tempo real, não se constituem em vantagem comparativa.

- Aumento da intensidade do conhecimento: há consenso em relação ao caráter estratégico com o qual se reveste o conhecimento organizacional, este traduzido por práticas e processos inovadores que resultam em novas tecnologias ou produtos, ou ainda em aplicações, capazes de gerar uma fonte crítica de vantagem competitiva sustentável.

Para que uma organização possa se adequar aos novos requisitos do ambiente de negócios, ela deverá desenvolver um determinado grau de flexibilidade estratégica, que pode ser resumida pelo "conjunto de capacidades de que se valha a empresa em resposta aos vários requisitos e oportunidades que se constituem os ambientes competitivos, dinâmicos e incertos" (HITT; IRELAND; HOSKISSON, 2002, p. 20).

A Gestão do Conhecimento oferece uma estrutura geral para a organização dos conteúdos estratégicos da aprendizagem, fortalecendo a capacidade de uma empresa em gerar respostas válidas aos desafios do ambiente externo em permanente estado de mudança, ampliando o portfólio de competências organizacionais, tendo em vista adaptar-se aos novos requisitos dos negócios e do ambiente tecnológico relacionado. Em razão do tema Gestão do Conhecimento ser considerado uma construção teórica em desenvolvimento, abre-se um espaço de debates e reflexões que visam introduzir novas perspectivas, ou mesmo referendar suposições acerca do tema. O papel que a Gestão do Conhecimento desempenha em termos de gerar maior competitividade para as empresas constitui uma das principais contribuições deste artigo.

\subsection{Objetivos do trabalho}

A pesquisa teve o objetivo de identificar alguns elementos teóricos que pudessem contribuir com o debate sobre a Gestão do Conhecimento, na sustentação da competitividade organizacional em uma empresa industrial nacional de alta tecnologia.

Outros objetivos, associados ao processo de pesquisa, visaram: a) identificar o grau de predominância do ambiente tecnológico institucional e do ambiente de negócios sobre a arquitetura da Gestão do Conhecimento; b) identificar os processos de negócio e competências mais fortemente visados pela Gestão do Conhecimento; e c) debater a contribuição da organização humana, esta compreendida pela Cultura Organizacional, Liderança e Recursos Humanos, na Gestão do Conhecimento no processo de geração e gestão do conhecimento. 


\subsection{Importância do tema e do objeto de estudo}

Persiste, no discurso acerca da tecnologia, o mito de que os produtos tecnológicos sejam necessariamente complexos, uma vez que decorrem de um conjunto sofisticado de conhecimentos científicos, raramente orientados para a comercialização. (MATTOS; GUIMARÃES, 2005, p. 5). Contudo, a tecnologia pode referir-se ao estado-daarte possível, dentro dos limites da sua aplicação. Como exemplo, os autores citam os contêineres, que, embora não tenham sido ancorados em sofisticados conhecimentos científicos, são, segundo os autores, "uma das tecnologias de maior sucesso no setor de transportes".

Os autores consideram a tecnologia, como um "conjunto organizado de todos os conhecimentos - científicos, empíricos ou intuitivos - empregados na comercialização de bens e de serviços (idem, ibid). Desse modo posto, a tecnologia é o resultado aplicado do conjunto de saberes sistemáticos transformados em produtos e serviços. Tais saberes, quando combinados a um grupo de fatores, tais como oportunidade, disponibilidade de informação e de capital, são devolvidos à sociedade na forma de produtos e soluções que influenciam o modo de vida da sociedade e os modelos de produção.

A Organização para Cooperação e Desenvolvimento Econômico - OCDE - (Apud AIAB, 2002) classifica como indústrias de alta tecnologia os setores: aeroespacial, computadores, eletrônicos e equipamentos de escritório e a indústria farmacêutica. Essas indústrias são aquelas que aportam os maiores investimentos em Pesquisa e Desenvolvimento de longo ciclo, e, conseqüentemente, elas estão mais expostas ao deslocamento das fronteiras tecnológicas que elas próprias geram na busca dos diferenciais competitivos, tendo como base a inovação dos produtos, serviços, processos, mercados e da tecnologia.

Tidd, Bessant e Pavitt (2005, p. 10) classificaram as inovações em quatro tipos, denominados os $4 P$ da inovação. São eles: a) inovação no produto: mudança nos produtos ou serviços oferecidos pela organização; b) no processo: mudanças na forma como os produtos são feitos e entregues ao mercado; c) posicionamento no mercado, que reflete os novos contextos para os quais os produtos são destinados; e d) no paradigma organizacional, que se refere ao modelo mental subjacente acerca da percepção do papel das organizações.

Para o conjunto de empresas classificadas como de alta intensidade tecnológica, os novos conhecimentos acerca dos produtos, dos processos, dos mercados e das pessoas, tendem a ser convertidos em decisões estratégicas, que afetam profundamente as prioridades e os esforços concentrados na sustentação do negócio. Assim sendo, a Gestão do Conhecimento, mais do que gerar competitividade, configura-se como um elemento essencial, de valor altamente estratégico para assegurar a perenidade da organização.
A transição do conceito de riqueza industrial, maquinário e na mão-de-obra intensiva, mudou o foco para o conhecimento como um potente instrumento de geração de diferenciais competitivos.

Portanto, este trabalho associa a Gestão do Conhecimento às características identificadas em uma empresa industrial nacional, do setor de alta tecnologia, respeitada pelo mercado competitivo como um dos maiores players da indústria mundial. Esse reconhecimento advém da sua capacidade de geração e aplicação de conhecimentos de alta tecnologia, os quais lhe permitiram atingir, três décadas depois, a autonomia na concepção e desenvolvimento de projetos, na gestão de parcerias de risco, com gradual nacionalização tecnológica, o que torna essa indústria um instigante objeto de pesquisa em Gestão do Conhecimento.

\section{RELEVÂNCIA TEÓRICA}

A busca do sucesso organizacional explica, em parte, o aumento do interesse sobre a Gestão do Conhecimento. Estabelecer um vínculo perene entre a melhoria contínua e a mudança adaptativa tem orientado, desde a década de 1950, em particular às empresas mais suscetíveis aos impactos das inovações, uma conduta de superação no modus operandi, nas funções organizacionais, tendo a eficiência máxima como meta a ser atingida (MORGAN, 1996).

A visão da eficiência absoluta foi reforçada pelo avanço da tecnologia aplicada ao trabalho e pelas repercussões dessa evolução sobre a capacidade de aprendizado da sociedade. Desse modo, a tecnologia aplicada ao trabalho transforma, não somente a natureza, mas, principalmente, a sociedade que daquele conhecimento se apropria.

Morais (1989) destacou os três grandes momentos do trabalho observados a partir dos impactos das mudanças na organização do trabalho sobre a sociedade: a) $\mathrm{O}$ racio- 
nalismo absoluto, sustentado pelo movimento iluminista, no século XVIII, no contexto da Revolução Industrial; b) A automatização do trabalho humano, que reforçou o mito da racionalidade ao transpor o tempo humano pelo tempo das máquinas; e c) A automação da sociedade que, a partir do surgimento dos computadores, passou a vivenciar o chamado tempo da máquina, ao suplantar o tempo do raciocínio humano pelo automatizado. Dessa forma, por meio da tecnologia, a sociedade industrial passa a experimentar uma mudança na caracterização das ferramentas e sistemas de controle dos sistemas produtivos, e a palavra-chave é a informação e, ao longo do tempo, o conhecimento.

A transição do conceito de riqueza industrial, antes baseado no capital financeiro, no maquinário e na mão-de-obra intensiva, mudou o foco para o conhecimento como um potente instrumento de geração de diferenciais competitivos: inovação, empreendedorismo e direcionamento do foco, antes na operação e processo, para a satisfação do cliente e da sociedade, por meio dos bens e serviços produzidos.

Dada a influência dos novos conhecimentos, aplicados na geração de novas tecnologias de trabalho e nos produtos, $\mathrm{o}$ presente trabalho estabeleceu como eixos conceituais temas a seguir abordados.

\subsection{A aprendizagem e o trabalho}

A ênfase dada à aprendizagem organizacional, a partir de 1950, é resultado da evolução das Ciências Sociais aplicadas ao ambiente produtivo. Pode-se relacionar a preocupação com a seleção e treinamento de pessoas como uma premissa para a obtenção de níveis cada vez maiores de produtividade. De fato, a produtividade passa a ser explicada sob duas vertentes: i) a organização técnica traduzida pelos recursos materiais, técnicos, tecnológicos e financeiros; e ii) a organização humana, compreendida a partir dos fenômenos psicossociais presentes nas relações interpessoais, nas expectativas humanas em relação ao trabalho e carreira, e nos elementos da cultura organizacional (FREITAS, 1991; SCHEIN, 1992).

Bennis (1976, p.112) explica que "desde fins de 1950, mais ou menos, a ênfase foi transferida do crescimento individual ao desenvolvimento organizacional". O autor define este desenvolvimento como uma estratégia educacional orientada para mudar crenças, atitudes, valores e estrutura das organizações.

Schön (1971) definiu a organização como um grande sistema social e epistemológico, constituído por: a) Estrutura - papéis que os indivíduos desempenham; b) Tecnologia, conjunto de normas, ferramentas e técnicas que visam alcançar as metas propostas; e por fim c) Teoria, regras epistemológicas que permitem compreender as realidades interna $\mathrm{e}$ externa ao ambiente organizacional. Schön, em parceria com Chris Argyris (Apud MAXIMIANO, 2002, p. 452), defendeu a aprendizagem organizacional contínua como um processo de mudança comportamental.

O princípio de aprendizagem de Senge (1990) baseia-se em três aspectos: a) para obter sucesso em ambiente em mudança contínua, as organizações devem estar em processo contínuo de aprendizagem; b) características organizacionais, como apego excessivo ao cargo, atribuição de culpa aos elementos exógenos, visão de curto prazo, dificultam o processo de aprendizagem; e c) o exercício de cinco disciplinas raciocínio sistêmico, objetivo comum, modelos mentais, aprendizagem em grupo e domínio pessoal - facilitaria a criação das organizações de aprendizagem.

Mattos e Guimarães (2005, p. 30) destacam a importância das organizações de aprendizagem no processo de inovação, o que envolve, até mesmo, a habilidade em "desaprender comportamentos e rotinas que não funcionam ou ficaram inadequados". Para os autores, "a inovação é a aplicação de conhecimento, a efetiva aquisição, armazenamento, recuperação e aplicação de conhecimento", etapas que remetem ao Ciclo da Gestão do Conhecimento, apresentado ao longo deste artigo, fortemente influenciado e viabilizado pela criação da cultura da organização de aprendizagem.

A aprendizagem pode ser vista sob duas perspectivas: como uma trajetória de acumulação de capacidade tecnológica, que pode mudar ao longo do tempo, em diferentes direções e velocidades; e como a soma dos "vários processos pelos quais os conhecimentos técnicos (tácitos) de indivíduos são transformados em sistemas físicos, processos de produção, procedimentos, rotinas e produtos e serviços da organização" (FIGUEIREDO, 2004, p. 328).

À perspectiva das organizações de aprendizagem seriam adicionados alguns elementos teóricos que pontuam a aprendizagem, em ambientes instáveis e circunstâncias complexas, como meio de geração de competências organizacionais, conforme será apresentado a seguir.

\subsection{A Complexidade e a formação das competências}

Morin (1990) influenciou a organização do conhecimento ao inserir no debate o fator complexidade, cujo paradoxo é conciliar fenômenos imprecisos e incertos, contrariando a noção de certeza e de equilíbrio constante trazida pela ciência normal. Esse debate foi iniciado por Prigogine (1996) nos anos 1970, ao referir-se ao caos e ao equilíbrio instável.

$\mathrm{Na}$ arena organizacional, a incerteza, indeterminações, fenômenos aleatórios e desequilíbrio amplificam a complexidade do processo gerencial, encaminhando, os setores mais expostos à variabilidade, ao modus operandi e decisório pautado na gestão do risco. 
A abordagem baseada em competências essenciais apropria alguns dos mais sofisticados conceitos de gestão, como os sistemas de acumulação flexível (HARVEY, 1996), que sugerem a noção de competências complementares obtidas mediante alianças e parcerias produtivas (KANTER, 1997) para a obtenção de vantagem competitiva (PORTER, 1989). Ou ainda pelo desenvolvimento de competências próprias, seja através das competências desenvolvidas na cadeia de valor; ou ainda a formação de economias de aglomeração e redes de cooperação produtiva (AMATO NETO, 2000; 2005).

Hamel e Prahalad (1995) evidenciaram a necessidade de uma arquitetura estratégica pautada na flexibilidade e mobilidade organizacional, para melhor atendimento das demandas voláteis do mercado, prontidão de resposta aos desafios estratégicos, desenvolvendo a capacidade de criar novos desafios, os quais determinam as vantagens competitivas.

O entrelaçamento entre formação de competências e estratégias empresariais foi também abordado por Fleury e Fleury (2000, p. 21-22), que afirmam que, "para ser considerado uma competência essencial, esse conhecimento (de operações de mercados específicos) deve ser associado a um sistemático processo de aprendizagem que envolve descobrimento/inovação e capacitação de recursos humanos" (FLEURY; FLEURY, 2000, p. 21-22).

Figueiredo (2004, p. 329), reconhece que a capacidade tecnológica está inserida: nos sistemas técnicos físicos de uma empresa: máquinas, equipamentos, sistemas, denominados como estrutura; nos conhecimentos e qualificação das pessoas: expressos pela experiência, pelas habilidades; nos sistemas organizacionais: modelos de gestão, técnicas de trabalho, normas e rotinas; nos produtos e serviços: desenho, prototipagem, testes, produção e entrega.

A discussão sobre a aplicação de um modelo de Gestão do Conhecimento perpassa o valor que os novos conhecimentos aportam para a capacidade adaptativa, em razão dos ambientes instáveis, e contribuem para a competitividade das organizações. Nas palavras de Sbragia et al. (2006, p. 79), “a gestão adequada do conhecimento torna-se, portanto, fator fundamental para a diferenciação estratégica e a construção de vantagens competitivas na empresa".

\subsection{A competitividade e a gestão do conhecimento}

Davenport (2001) define o conjunto de vantagens geradas pela estrutura industrial como capacidades organizacionais, dispondo que elas estão inseridas nos seguintes grupos: a) capital humano baseado nas habilidades e conhecimentos requeridos; b) estrutura organizacional, compreendida como um padrão de relacionamento entre as unidades e os indivíduos; c) processos de trabalho; e d) tecnologia aplicada na produção de bens, serviços e às informações. O fluxo de geração de vantagem competitiva ocorreria nos seguintes passos: 1) definição das estratégias; 2) definição das capacidades organizacionais para implantação das estratégias; e 3) acionar as alavancas de implantação.

\section{conhecimento organizacional deve ser uma
construção propositada que tenha como foco desenvolver um conjunto diferenciado de habilidades,} crenças, valores, atitudes e comportamentos.

Hitt, Ireland e Hoskisson (2002) destacam três níveis de conhecimento imprescindíveis à competitividade. São eles: a) informação sobre o conjunto de recursos e infra-estrutura organizacional que viabilizam as operações; b) inteligência do negócio, que concentra as informações sobre o ambiente externo, desempenho passado e eventos relevantes, além de previsões e tendências; e c) expertise, refere-se à vocação essencial do negócio e à capacidade da organização em manter-se competitiva e atualizada, ao mesmo tempo em que inova e atende às necessidades de adaptação impostas pelo ambiente competitivo.

Os três níveis de conhecimento destacados por Hitt, Ireland e Hoskisson (2002) devem ser integrados. Sbragia et al. (2006, p. 81) explicam que "foi partindo da idéia de integração e do estímulo ao aprendizado intra-organizacional que muitos consultores e acadêmicos popularizaram, a partir da década de 1990, o conceito de Business Intelligence (BI).

Contudo, para que o valor do conhecimento seja adotado na práxis organizacional, com a agilidade compatível com as mudanças verificadas no meio externo, é indispensável dotar a organização de um adequado nível de flexibilidade estratégica, ou seja, transformar a capacidade adaptativa em vantagem sobre a conduta estratégica dos seus concorrentes.

Os diversos autores pesquisados opinam que o conhecimento organizacional deve ser uma construção propositada que tenha como foco desenvolver um conjunto diferenciado de habilidades, crenças, valores, atitudes e comportamentos, formando uma cultura organizacional (SCHEIN, 1992) voltada à mudança e que crie uma perspectiva de alcance de resultados superiores (PORTER, 1989; NONAKA; TAKEUCHI, 1997). 
D'Aveni (2001) caracteriza o momento competitivo como de crescente rivalidade na inovação rápida dos produtos, nos menores ciclos de vida de projeto e de produto, competição agressiva com base em preço e competência e experimentação de novas abordagens para atender às necessidades do consumidor. disponibilidade dos fatores de produção e pelas demandas ambientais com as quais essas organizações lidam; e c) tecnologia, que está relacionada aos recursos de hardware e software que apóiam a tomada de decisão e a gestão de informações e conhecimento.

A organização, contudo, não pode ser vista exclusivamente como uma processadora de informações (NONAKA; TAKEUCHI, 1997). A noção dada por esses autores para a criação do conhecimento organizacional e da inovação considera a capacidade humana de gerar conhecimento a partir de elementos intangíveis, tais como: intuição, ideais, valores, emoções, imagens e símbolos, como recursos da criação de novos conhecimentos.

Desse modo, existem fatores intangí-

Day (2001) afirma que a vantagem competitiva, para ser duradoura, implica a adoção do círculo virtuoso da lealdade, por meio do qual a empresa investe continuamente no desenvolvimento de aptidões, ou competências, tendo como foco a obtenção de níveis de satisfação e lealdade dos clientes. Ou seja, a lealdade resulta do atendimento da expectativa de solução tecnológica pelo cliente.

Fleury e Fleury (2000, p. 43-55) afirmam a necessidade de alinhamento entre as estratégias e as competências, justificada pelas seguintes perspectivas de análise: a primeira relacionada ao modelo competitivo da indústria, que evoca o desenvolvimento de competências e tendências de inovação na indústria, e a segunda perspectiva está baseada na adequada inovação dos recursos internos da organização (resource basead view of the firm), tangíveis e intangíveis, como forma de estabelecer um balanço entre as condicionantes competitivas de mercado, estratégias competitivas e competências essenciais.

Especificamente no caso de empresas que pautam sua competitividade na formação de competências inovadoras, e dinâmicas, ressaltam Tidd, Bessant e Pavitt (2005, p. 127), que embora não haja "receita" e ferramentas que garantam o sucesso, "em todos os casos, a capacidade de aprender a partir das experiências já vividas é essencial", ou curva de aprendizado, como meio de apropriação dos erros e acertos, principalmente dos primeiros, no processo de análise sobre produtos, serviços e mercados.

Angeloni (2002) propõe um modelo tridimensional de organização do conhecimento, composto por: a) infraestrutura organizacional, que se refere ao ambiente organizacional, comportamento e atitudes; b) pessoas, os principais agentes de transformação, tendo em perspectiva o fato do uso da autonomia nas organizações estar delimitado pela veis que influenciam a geração e aplicação de conhecimento, inerentes à forma como os indivíduos percebem o valor da aplicação de certo grau de subjetividade que caracteriza o potencial de aplicação dos novos conhecimentos aos produtos, processos, tecnologia e às pessoas. $\mathrm{O}$ conjunto de fatores explícitos, ou formais, e implícitos, ou intangíveis, reside nas dimensões do conhecimento, a seguir apresentadas.

Compreender as dimensões contidas na Gestão do Conhecimento permite estabelecer uma estratégia de ação e de definição de abordagem e conteúdo. Santos (2004) debate, a partir do legado do pensamento socrático, quatro dimensões do conhecimento: a) mitológica, refere-se àquilo que se pretende eternizar por meio do conhecimento, o próprio negócio ou uma competência distintiva; b) cosmológica, define os limites espaço-temporais que a organização pretende ocupar, física ou virtualmente; c) sociológica, ou inserção do indivíduo ao grupo de trabalho, a partir do conhecimento; d) pedagógica, ou processo estruturado da aprendizagem, instrumentos e recursos aplicados na disseminação do conhecimento.

A geração do conhecimento deve ser compatível com a visão de futuro, com as estratégias de desenvolvimento de competências e com o aporte tecnológico necessário para amparar os sistemas de controle do desempenho, em todos os níveis.

Santos (2004) descreve três níveis de demanda ou espaços que a construção do conhecimento deve observar. São eles: a) Epistemologia, ou teoria do conhecimento, que tem na metodologia um instrumento de articulação entre os métodos de verificação e os principais enunciados teóricos; b) Antropologia, ou identificação da influência dos fatores

\section{DIMENSÕES DO CONHECIMENTO}


antropológicos no processo de criação de conhecimento e transferência de conhecimento; e c) a práxis, que se refere ao uso de um conjunto de saberes organizados por meio de um método ou operação para alcançar um dado resultado. Para atingi-lo é necessário combinar habilidades técnicas, éticas e sensoriais, como a intuição.

Na perspectiva de ampliar o debate da Gestão do Conhecimento para a formação da Inteligência organizacional, Albrecht (2004) propõe um modelo cujo pressuposto é a identificação de gaps de inteligência, migrando do enfoque da tecnologia para a estratégia de gestão e, deste, para a formação do gestor. No modelo proposto, coexistem sete dimensões-chave de competência e conhecimento especializado sobre a organização e seu ambiente de atuação, a saber: a) visão estratégica, ou direcionamento; b) percepção de destino compartilhado, ou uma finalidade comum; c) apetite por mudanças, ou criação de novas formas de conceber o sucesso da empresa; d) "coração": entusiasmo para aplicar um nível de energia extra para que a empresa obtenha sucesso; e) alinhamento e congruência: corresponde à disponibilidade infra-estrutural necessária para que a organização atinja sua visão estratégica; f) uso do conhecimento: capacidade de desenvolver e aplicar novos conhecimentos; e g) pressão por desempenho: que pode ser definida como o engajamento com que cada empregado se mobiliza, e contagia os demais, visando atingir os resultados propostos.

Se, por um lado, a distinção entre as dimensões permite identificar as estratégias de geração do conhecimento, por outro, observa-se que a clareza na identificação da tipologia do conhecimento é um elemento essencial à composição dos conteúdos e da abordagem metodológica a ser utilizada para a movimentação do Ciclo da Gestão do Conhecimento geração, armazenagem, distribuição e aplicação de conhecimento, em moto contínuo.

\subsection{Tipos de conhecimento}

Nonaka e Takeuchi (1997) evidenciaram dois conjuntos de conhecimento: tácito, resultante da vivência do indivíduo; e explícito, ou documentado, resultante de processos formais e estruturados de aprendizagem.

Chai (2000) identificou o conhecimento de processo, como direitos de patente e documentação de projetos, e o conhecimento de pessoas, que envolve habilidades de relacionamento, percepções do ambiente e outros, como elementos socializáveis do conhecimento. E acrescenta mais um tipo de conhecimento contextualizado, ao qual denomina de conhecimento local, concluindo que existe um mecanismo de transferência apropriado à natureza de cada tipo de conhecimento.

Um quarto tipo de conhecimento foi denominado por
Granger (1989) como o conhecimento sensivel. Este é intransferível na sua totalidade, senão através de metáforas, pois é capturado a partir dos sentidos e da percepção de significado contida.

\section{PROCEDIMENTOS METODOLÓGICOS}

Dado tratar-se de uma abordagem qualitativa, as estratégias de investigação basearam-se em um estudo de caso único, aplicado em uma indústria de base tecnológica. O estudo de caso é recomendável, quando o pesquisador deseja expandir ou generalizar teorias, o que atendeu às proposições deste trabalho e contemplou as exigências da abordagem escolhida (YIN, 1984).

Quanto aos procedimentos de coleta de dados, esta pesquisa baseou-se na análise de documentos históricos e na literatura disponíveis (PÁDUA, 1989), permitindo melhor compreensão acerca das estratégias adotadas para gerar competitividade e dos modelos mais recentes de Gestão de Conhecimento. Somaram-se, ainda, à coleta de dados, as entrevistas semi-estruturadas, previamente orientadas por um roteiro de oito questões, feitas a uma amostra dirigida de executivos da empresa; e a aplicação de questionários para um segundo grupo de profissionais da indústria, escolhidos por critério de acessibilidade.

As informações obtidas, na entrevista, foram agrupadas segundo a categoria de respostas, e analisadas de acordo com o conteúdo apresentado; já as informações do questionário foram tabuladas, e apuradas mediante cálculo das médias ponderadas, obtidas pela freqüência de respostas na escala de avaliação oferecida, e pelo cálculo da média aritmética simples para identificação do ambiente predominante, a partir dos fatores avaliados.

Além dos elementos teóricos apresentados, a organização da pesquisa baseou-se na busca de respostas para as proposições indicadas no Quadro 1.

As considerações obtidas nos elementos teóricos do trabalho, modelo de referência e os resultados obtidos estão apresentados a seguir.

\section{MODELO DE REFERÊNCIA PARA A PESQUISA}

A pesquisa bibliográfica conduziu a um modelo de referência de Gestão do Conhecimento desenvolvido pelos pesquisadores do Instituto Fraunhofer, cuja aplicação envolveu um estudo de campo com 164 empresas, das quais mais de dois terços enquadram-se como empresas de alta intensidade tecnológica, de um universo total de 
1200 empresas européias de sucesso (MERTINS; HEISIG; VORBECK, 2003). A Figura 1 apresenta o modelo.

Uma das contribuições deste modelo de Gestão do Conhecimento refere-se aos três níveis propostos de ação: o primeiro deles estabelece que a Gestão do Conhecimento deva ser focada permanentemente em valor adicionado aos processos de negócio, isto porque esses definem o campo ou domínios do conhecimento.

\section{Quadro 1: Proposições da pesquisa.}

Motivação da pesquisa: Como uma indústria de base tecnológica, com um lead time, pode gerar conhecimento e inovação, dado o rápido deslocamento das fronteiras tecnológicas, tendo como elementos facilitadores o desenvolvimento de recursos humanos, a transformação da cultura organizacional e a formação da liderança?

Questão Central: O Modelo de Gestão de Conhecimento em indústrias de base tecnológica é mais sensível ao modelo de desenvolvimento tecnológico da indústria ou ao modelo de gestão de negócio?

\section{Questões secundárias:}

Quais são os principais processos formais que sustentam o Ciclo de Gestão do Conhecimento?

Como envolver a cadeia de parceiros estratégicos no Ciclo de Gestão de Conhecimento e Inovação, garantindo, ao mesmo tempo, a exclusividade das vantagens obitidas?

Proposição Básica: A Gestão do Conhecimento na indústria de base tecnológica apóia-se em um amplo espectro de agentes institucionais, o que viabiliza gaps cada vez menores em relação ao rápido deslocamento das fronteiras tecnológicas.

\section{Proposições Secundárias:}

As inovações tecnológicas representariam saltos qualitativos em relação à funcionalidade já existente, tratando-se, portatnto, de melhoria contínua e não necessariamente de inovação.

Todo novo projeto, em produção, representaria um gap tecnológico somente compensável nas novas versões do produto, nas quais se repetiria o ciclo de obsolescência acelerada.

Fonte: Os autores, 2007.

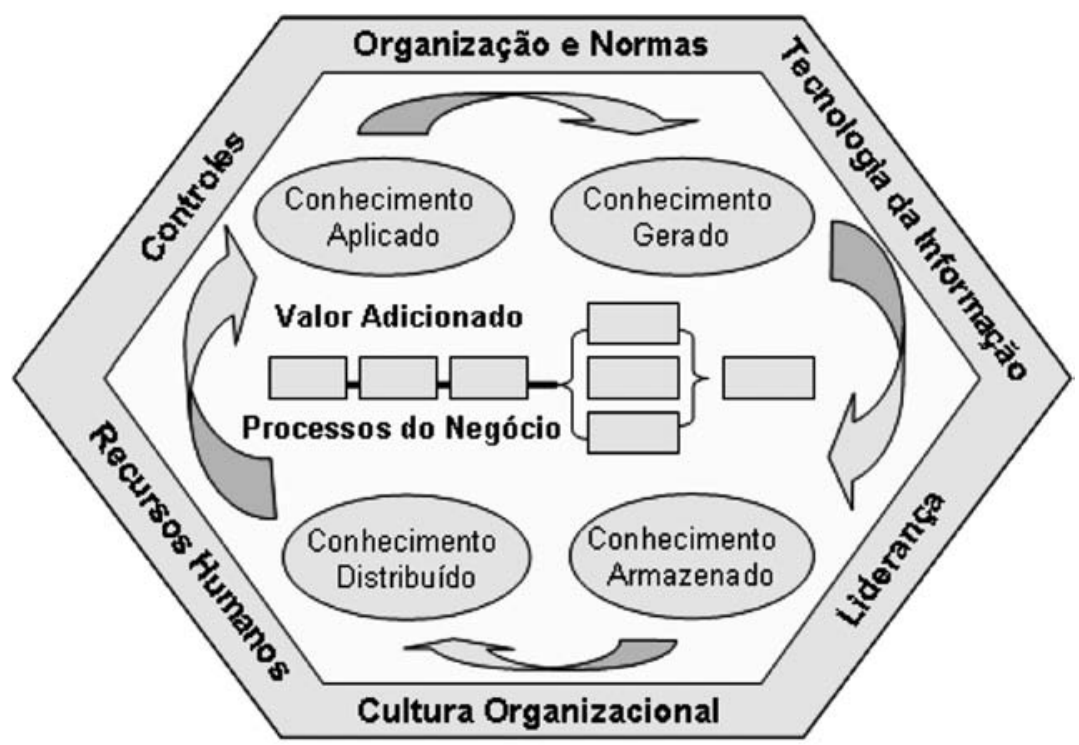

Figura 1: Áreas definidas para a gestão do conhecimento.

Fonte: MERTINS; HEISIG; VORBECK, 2003. 
O segundo nível refere-se aos processos essenciais de gestão do conhecimento divididos em quatro grupos de atividades. São eles: criação de novos conhecimentos, armazenamento dos conhecimentos, distribuição (transferência) e aplicação do conhecimento.

O terceiro nível é designado "Áreas Definidas para a Gestão do Conhecimento" ou campos definidos para a Gestão do Conhecimento, como: cultura organizacional, liderança, recursos humanos, tecnologia da informação, organização e normas, e sistemas de controle.

Os cinco itens são derivados dos fatores críticos de sucesso, identificados na pesquisa conduzida pelo Instituto. O sexto item - sistemas de controle - é considerado um pré-requisito para mensurar os resultados obtidos com as atividades de Gestão do Conhecimento.

Tendo como base o modelo proposto, a constatação de que os campos definidos envolvem dois agrupamentos organizacionais distintos - a organização técnica e a organização humana - e que o recorte epistemológico da pesquisa referese a este último grupo, formulou-se um modelo inicial, descrito na Figura 2.

Os elementos facilitadores referem-se às áreas definidas para a Gestão do Conhecimento propugnadas no modelo cotejado nesta pesquisa, como um recorte da análise do modelo epistemológico total. O resultado será apresentado no tópico a seguir.

\section{Resultados da pesquisa}

Foram identificados três aspectos facilitadores da geração do conhecimento: o primeiro referente ao contexto histórico e político da formação da indústria e o envolvimento do Estado na escolha da indústria para nacionalização tecnológica, ou seja, os elementos da Cultura Organizacional. O segundo aspecto refere-se ao contexto particular do setor, tendo em vista a amplitude das ciências envolvidas e a formação de um pólo tecnológico nacional. O terceiro aspecto está relacionado ao engajamento dos indivíduos em torno de um objetivo comum ao longo do desenvolvimento da indústria. Neste terceiro aspecto contribuem para a geração do conhecimento os seguintes elementos: a Liderança e o conjunto dos Recursos Humanos.

A análise da sensibilidade do modelo de Gestão do Conhecimento do ambiente tecnológico e do ambiente de negócios, dada a média aritmética simples (MAS) dos quinze fatores avaliados, revelou haver uma influência discretamente maior dos fatores relacionados ao ambiente de negócios (MAS 7,9) em relação ao ambiente tecnológico (MAS 7,5). Contudo, na avaliação da importância de cada ambiente houve um equilíbrio quase perfeito entre os fatores do ambiente de negócios (MAS 7,6) e do ambiente tecnológico (MAS 7,5).

Os processos que sustentam a Gestão do Conhecimento são os seguintes: a) Relacionados à Operação: Desenvolvimento Tecnológico, Concepção de Produtos, Sistemas

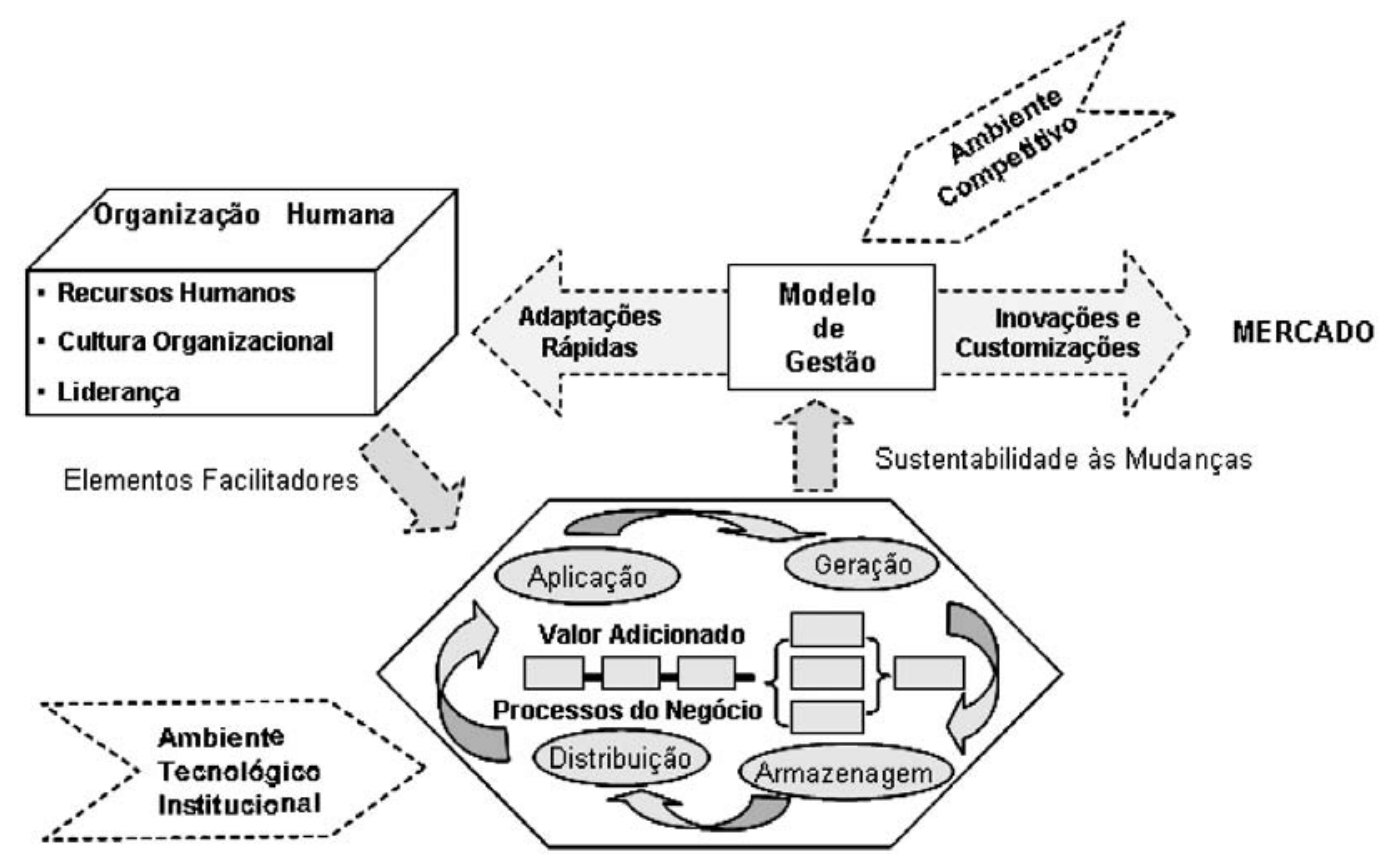

Figura 2: Gestão do conhecimento em indústrias de alta tecnologia.

Fonte: Os autores, 2007 
de Manufatura, Gestão de Parcerias Estratégicas, Gestão Estratégica de Negócios e Gestão de Clientes; b) Relacionados à Gestão e ao Apoio: Educação Continuada, Gestão do Desempenho (Programa de Ação), Gestão da Informação, Gestão da Melhoria e da Mudança.

A Figura 3 descreve o modelo resultante da análise dos processos de negócio que sustenta, e justifica, o modelo da Gestão do Conhecimento na indústria investigada.

Sobre a questão relacionada ao envolvimento da cadeia de parceiros estratégicos no Ciclo de Gestão do Conhecimento e garantia de sigilo, apurou-se que as parcerias estratégicas são pautadas no risco e ganho compartilhados.

Contudo, e apesar da relação ser regida por contrato, as vantagens obtidas pelo investimento em desenvolvimento tecnológico feito por parceiros são de propriedade e de direito desses parceiros, a cada um de acordo com sua responsabilidade e participação no projeto. Portanto, o direito de comercialização do produto resultante é do parceiro. Porém, a especificidade do projeto pode restringir o campo de uso.

Sobre as proposições da pesquisa, observou-se que a gestão do conhecimento apóia-se em um amplo espectro de agentes institucionais, presentes desde a formação da indústria, o que viabiliza gaps cada vez menores em relação ao rápido deslocamento das fronteiras tecnológicas. A cultura organizacional, como elemento facilitador, estabelece o desafio da Educação Continuada, o que contribui para a manutenção dos níveis de conhecimento tecnológico atua- lizados. Há um forte investimento na aceleração do ciclo vivencial dos engenheiros trainees, que são submetidos a um programa intensivo de especialização aeronáutica, com o apoio de Instituições de Ensino Superior e dos grupos de especialistas internos, ou seniores.

Porém, a redução absoluta dos gaps tecnológicos somente seria possível se houvesse um processo de aquisição regular dos produtos de alta tecnologia pelos setores do governo, em razão do fluxo contínuo de geração de conhecimento e de inovação tecnológica ao longo lead time do produto, o que não ocorre. Além disso, as agências de fomento não possuem suficiência de recursos para atender o nível de investimento necessário para desenvolvimentos de vulto. Portanto, o processo de financiamento da Pesquisa e Desenvolvimento resulta das vendas realizadas pela empresa.

Quanto às inovações tecnológicas, em razão do longo ciclo de vida do produto, estas se referem mais freqüentemente à melhoria contínua do que a mudanças radicais. Neste sentido contribuem tanto os líderes quanto os liderados, que contam com os Grupos de Melhoria Contínua. Além disso, contribuem também os programas institucionais de sugestões dos empregados, o que tem trazido contribuições efetivas para a empresa, influenciando, por exemplo, a redução dos ciclos, o que representa considerável ganho de competitividade.

Quanto aos gaps tecnológicos, concluiu-se que, de fato, o longo ciclo de vida do produto inviabiliza o uso do estado-da-

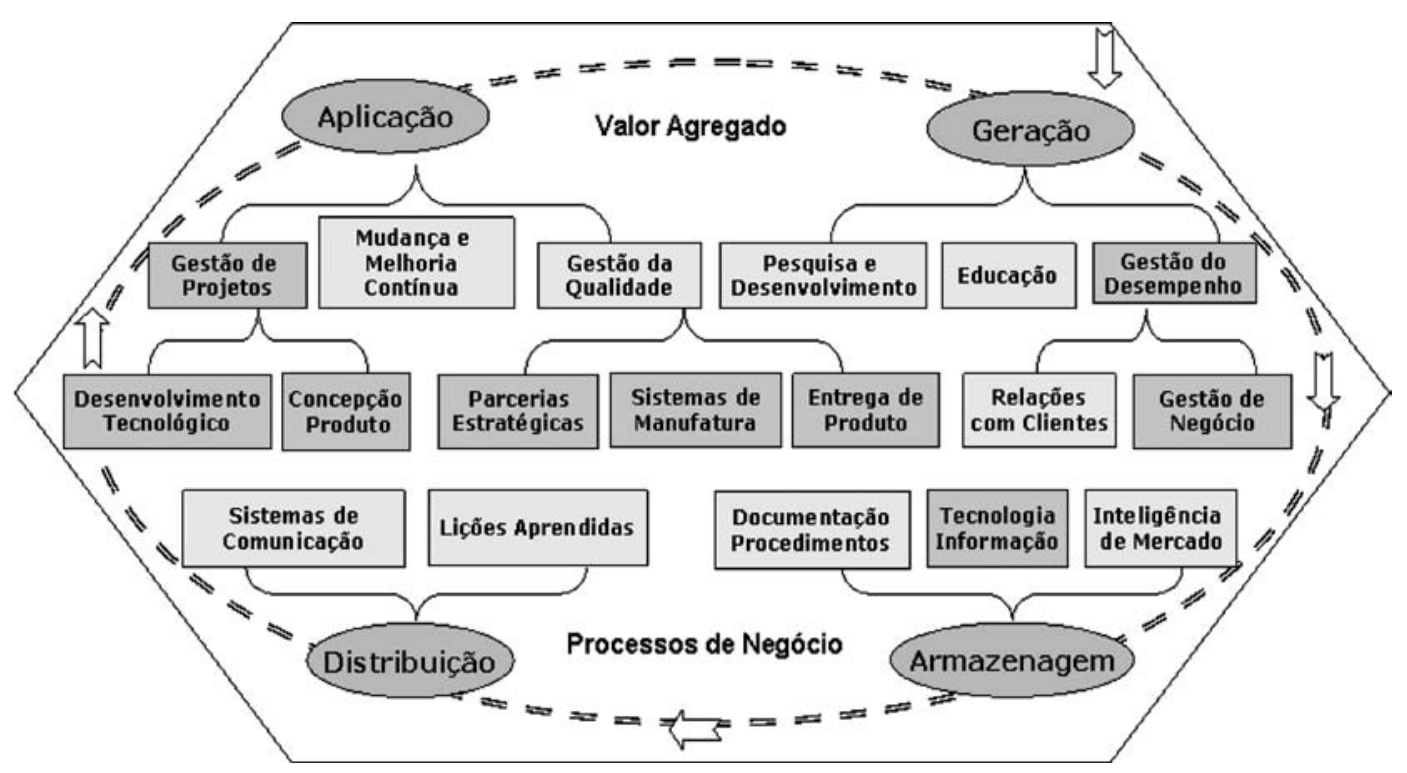

Figura 3: Áreas do conhecimento e processos de negócio.

Fonte: Os autores, 2007. 
arte em tecnologia. Contudo, o conhecimento acumulado, as lições aprendidas e a adequada percepção das oportunidades imprimem nos novos produtos os aspectos mais atualizados, sejam essas melhorias associadas ao desempenho, custos ou à customização.

\subsection{Outras contribuições}

No início da formulação do modelo e para efeito de orientação da pesquisa foram formuladas algumas questões, cujo resultado está apresentado a seguir:

1. Quais seriam os principais agentes do ambiente tecnológico institucional e o nível de relacionamento destes com o fluxo de inovações tecnológicas e estruturais naquela indústria?

Um dos principais agentes do ambiente institucional é o governo, por meio das compras do setor Militar. Os demais agentes não têm recursos suficientes para alimentar o processo de $\mathrm{P} \& \mathrm{D}$ da indústria.

2. Na fase de formação da indústria, o conhecimento tinha um caráter de crescimento incremental, mobilizado principalmente pelo desenvolvimento tecnológico do setor, particularmente orientado pelo setor da Defesa. Desse modo, pode-se afirmar que a ênfase da Gestão do Conhecimento era de caráter técnico?

Há consenso que, desde o início, a empresa desenvolveu suas competências tecnológicas e mercadológicas, ainda vigentes no modelo atual desde o início da indústria.

3. É correto afirmar que nessa fase a empresa era vista como uma "empresa local com um mercado internacional", formando uma forte cultura de fábrica estatal de aviões?

A cultura organizacional decalcou dois grupos distintos. O primeiro grupo, voltado para a liderança política, com maior permeabilidade no ambiente político e tecnológico institucional, e visão estratégica do mercado; e o segundo grupo, formado pela liderança operacional, a qual reconhece a cultura como claramente orientada para ser uma fábrica estatal de aviões.

4. Em decorrência do modelo autárquico, os fatores associados a Recursos Humanos privilegiavam, basicamente, as contratações locais e nacionais e o conhecimento técnico?

O ITA e a FAB eram os principais provedores de profissionais altamente qualificados em Engenharia Aeronáutica e áreas correlatas, e em aviação, engenharia e ensaios de vôo - pilotagem. O principal instrumento de geração de conhecimento utilizado baseou-se na Educação Continuada na área aeronáutica para os profissionais considerados pes- soas-chave e potenciais multiplicadores do conhecimento. $\mathrm{O}$ ambiente interno promovia o trabalho cooperativo, e a ação de Desenvolvimento de Pessoas pautava-se na premissa do conhecimento do "como fazer" e do "por que fazer" - knowhow e know-why.

5. O perfil da liderança era tecnicamente orientado e a visão de carreira privilegiava a formação de engenheiros, qualquer que fosse a área?

Ao perfil técnico inicial, competências tecnológicas, mercadológicas e empresariais - com foco no desempenho financeiro e gestão estratégica de negócio - marcaram uma passagem importante no perfil da liderança, prevalecendo até os dias atuais a formação técnica nas ciências aeronáuticas e nas engenharias, com exceção de áreas especialistas, como a Jurídica, por exemplo.

\section{uanto ao envolvimento da cadeia de parceiros} garantia de sigilo, apurou-se que as parcerias estratégicas são pautadas no risco e ganho compartilhados.

6. Com a mudança do modelo de gestão, quando da reconfiguração societária, a Gestão do Conhecimento passou do enfoque técnico para o foco sistêmico, privilegiando o posicionamento competitivo da empresa?

Desde o seu nascimento a empresa foi posicionada no nicho de mercado regional de pequeno porte. Pode-se associar a competência empresarial resultante da mudança no perfil de acionistas como um propulsor do ingresso da organização no nicho acima de 50 assentos, aproveitando as condições disruptivas - ou seja, as tendências de demanda do produto no mercado de médio porte, a infra-estrutura industrial já instalada e a baixa concentração de manufaturas de grande porte - e o bom desempenho das parcerias de risco. Pode-se correlacionar a mudança do modelo de gestão autárquica, caracterizada pela escassez de recursos e pela baixa autonomia, para o modelo de gestão privada, caracterizada pelo acompanhamento dos resultados financeiros (governança corporativa) e pela expectativa de retorno sobre o investimento dos acionistas. As ações vinculadas a essa passagem no modelo de Gestão do Conhecimento têm mais o caráter de distribuição de uma nova prática de gestão baseada em resultados.

7. O conhecimento gerado ao longo da formação das competências da indústria permitiu reduzir o nível de dependência de fornecedores - de tecnologia, sistemas, partes e materiais - internacionais? 
O setor tinha um nível inicial de $100 \%$ de dependência dos fornecedores internacionais. Nos anos que antecederam a mudança do modelo de gestão, com o desenvolvimento do EMB 145, o nível de internacionalização do produto reduzira-se para $75 \%$. Atualmente, o produto exibe um nível de nacionalização de $50 \%$.

8. A dinâmica do ambiente de negócios associado ao conjunto de competências de desenvolvimento e concepção de produtos, e a visão do mercado de internacional para global, além das condições disruptivas, apontaram a necessidade de orientação estratégica das capacidades organizacionais para um novo nicho de mercado, caracterizado pelo médio porte das aeronaves - entre 70 e 108 assentos.

A mobilização dos recursos para o ingresso da empresa em um novo nicho de mercado decorre, de fato, da necessidade de a organização buscar competitividade em segmentos mais promissores, de acordo com as tendências da indústria. As informações obtidas nas entrevistas indicam o fortalecimento nas competências de desenvolvimento de projeto e concepção de produtos.

\section{CONSIDERAÇÕES FINAIS E CONCLUSÕES}

Esta pesquisa apresentou o modelo de Gestão do Conhecimento em uma indústria de base tecnológica, evidenciando algumas dicotomias relevantes, como a questão da autonomia; desconcentrou a ênfase nos elementos da organização técnica, sobretudo na tecnologia da informação que, nesta pesquisa, é vista como um recurso organizacional; desenvolveu um instrumental de pesquisa com embasamento teórico atualizado, apoiado por um extenso levantamento bibliográfico; adicionou contornos mais flexíveis ao tema, além de contemplar a informação e a inteligência formada em torno do ambiente competitivo e do ambiente organizacional, buscando oferecer, assim, uma perspectiva orgânica sobre a questão da Gestão do Conhecimento.

A motivação da pesquisa pode ser desdobrada em três outras questões relevantes:

a) É possível gerar conhecimento e inovação tecnológica em empresas industriais de produtos com longo ciclo de concepção, desenvolvimento e produção? No caso desta pesquisa concluiu-se que as inovações estão limitadas aos conteúdos conhecidos das ciências e das suas aplicações. Desse modo, a obtenção de melhoria em relação ao desempenho das aplicações atuais, ou mesmo de novas aplicações, já seria uma evolução considerável, ainda que não necessariamente uma inovação tecnológica, no padrão de mudanças bruscas. O longo lead time inicia-se com a descrição da disponibilidade tecnológica no momento da concepção do produto. Essa disponibilidade tende a ser a mesma ao final do ciclo.

b) A indústria é agente ou sujeito do rápido deslocamento das fronteiras tecnológicas? À exceção dos países que tenham extensos programas de financiamento ao desenvolvimento tecnológico, a indústria de base tecnológica nacional é, primariamente, o principal agente da geração de novas tecnologias, desde a definição das prioridades de desenvolvimento até o financiamento dos programas para geração de novos conhecimentos. Em alguns casos, os acordos de cooperação entre países, decididos em nível político e executados com base em modelos de colaboração interorganizacionais, preenchem a lacuna do investimento governamental. Porém, circunstâncias como essas ocorrem, novamente, por exceção.

c) De que forma os elementos que compõem a organização humana - recursos humanos, liderança e cultura organizacional - podem ser articulados em torno do conhecimento e da inovação, considerando a velocidade com que surgem novos requisitos e exigências do ambiente tecnológico e competitivo? Os resultados desta pesquisa apontam que houve consenso sobre a importância da organização humana, revelada na preocupação da organização em manter seus ativos intelectuais atualizados em relação às inovações, por meio do processo de educação contínua, capacitação profissional e formação da liderança. Com relação à cultura organizacional, as principais alavancas de sustentação da competitividade tecnológica estão pautadas em melhoria contínua, foco na satisfação do cliente e, mais recentemente, foco na satisfação do acionista.

A transferência dos elementos da competitividade tecnológica para a geração das competências interpessoais inclui os seguintes aspectos: desenvolvimento da visão estratégica, alinhamento e orientação para alcance dos objetivos da organização, percepção do resultado compartilhado, capacidade de mudanças rápidas e quebra sistemática de modelos mentais ultrapassados, pressão contínua por melhoria de desempenho, o conhecimento como recurso compartilhado e, sobretudo, vínculo emocional com o produto e com a organização.

Em relação ao modelo proposto, alguns aspectos devem ser destacados: O primeiro deles refere-se ao fato inovador em comparação ao modelo proposto pelo Instituto Fraunhofer, que concentra, basicamente, suas análises em fatores associados à organização humana, sem, contudo, desconsiderar os elementos da organização técnica, inseridos no conteúdo dos processos de negócio. Desse modo, 
a tecnologia da informação, sistemas de controle, normas e organização assumem características instrumentais aos processos de negócio e às etapas inerentes ao ciclo de Gestão do Conhecimento, como, por exemplo, o armazenamento e a distribuição do conhecimento. O segundo ponto a ser destacado refere-se ao fortalecimento das competências humanas e técnicas relacionadas à aplicação do conhecimento, como visão estratégica, domínio da função, tomada de decisão e risco. Esse breve conjunto de competências aponta como prioridade da Gestão do Conhecimento definir os graus de autonomia necessários à inovação e à criação de uma cultura organizacional efetivamente orientada para a melhoria contínua. O terceiro aspecto que o modelo evidencia é o papel da liderança como um elemento facilitador da aproximação dos indivíduos aos conhecimentos disponíveis e à melhoria contínua do desempenho através de instrumentos de gestão de pessoas, como a Avaliação de Desempenho ou Plano de Metas, associados à conduta indispensável de coaching. O quarto elemento caracterizado no modelo e avaliado ao longo da pesquisa é a influência do modelo de gestão de negócios na grade dos programas associados à Gestão do Conhecimento. Desse modo, o modelo de negócios direciona os conteúdos e as ênfases da Gestão de Conhecimento, ao definir o elenco de prioridades do negócio, transformando-os em meio de obtenção de respostas rápidas - ou prontidão de resposta, como é chamada na empresa pesquisada - às novas demandas do ambiente competitivo, que pressiona o modelo de gestão por melhores desempenhos, ao mesmo tempo em que essas retornam na forma de inovações tecnológicas e na forma de customizações. O quinto elemento representado no modelo - Ambiente Tecnológico Institucional -, inserido exclusivamente nesta pesquisa, apresentou um resultado diferenciado em relação aos modelos associados à Gestão do Conhecimento em indústrias de base tecnológicas, em países da Europa, no Japão e nos Estados Unidos: a inexistência de apoio governamental, de fato representativo, na pesquisa e no desenvolvimento tecnológico brasileiro, ao contrário do que ocorre nos países mencionados. Todavia, essa característica, por não ser foco desta pesquisa, não foi aprofundada.

Outras observações de caráter geral evidenciam as principais dificuldades com a abordagem aos elementos da organização humana, tais como: estabelecer o afastamento crítico por parte dos respondentes, o que induziu à criação de um sistema de notação numérica, com a aplicação dos critérios de média ponderada. Isto permitiu diluir os aspectos sub- jetivos da análise. Outra observação relevante ao contexto da pesquisa de campo é a mistura entre a satisfação dos entrevistados em contribuir com uma pesquisa de um tema relevante e o orgulho por ser participante ativo da Geração do Conhecimento.

Observou-se a necessidade de alinhar a Gestão do Conhecimento aos parâmetros de relacionamento da empresa com os seus ambientes de influência, ou seja, a instância política, a instância tecnológica e o ambiente de negócios, neste compreendidos os clientes, as agências de financiamento, a concorrência, os parceiros, os fornecedores. Outro aspecto a ser destacado diz respeito à relativização dos resultados da pesquisa: por mais amplos que possam ser os modelos de Gestão do Conhecimento, é imprescindível particularizar as características da organização, tenham elas reflexos exógenos ou endógenos.

Ainda, é necessário contextualizar o momento histórico, político e econômico, tecnológico, cultural e social que caracteriza as orientações do modelo de Gestão de Conhecimento em uma empresa de base tecnológica, que difere de outra, ainda que classificadas no mesmo grupo; ou seja, não foi identificado um modelo de aplicação universal. Além disso, há necessidade de considerar os novos requisitos trazidos pela incerteza e pela indeterminação do comportamento das variáveis macroambientais.

O modelo destaca a necessidade de compartilhar os propósitos da organização e, sobretudo, de clarificar os aspectos tidos como valiosos e perenes. Há que se combinar um conjunto de capacidades e ferramentas que permitam intensificar a interação entre a organização humana e a organização técnica, visando maior efetividade nas trocas interpessoais e dos indivíduos com a organização. E, sobretudo, efetivar a Gestão do Conhecimento como um processo em contínua evolução, criando uma comunidade crítica, com maturidade para ousar e desafiar paradigmas, sejam eles tecnológicos, mercadológicos ou organizacionais.

A inovação passa necessariamente pela crítica madura ao que já existe e pela criatividade de reinventar soluções e, novamente, pela autonomia e também pela tolerância ao erro.

No caso da indústria aeronáutica brasileira, o conhecimento foi construído a partir do ideário do desenvolvimento industrial, substituindo o modelo agrário, até então predominante, o que exigiu criação da infra-estrutura básica. Uma generalização deve considerar os limites da base histórica e política do contexto da nação.

\section{Artigo recebido em 08/08/2006 Aprovado para publicação em 03/06/2008}




\section{REFERÊNCIAS}

AIAB - Associação das Indústrias Aeroespaciais do Brasil. Tecnologia aeroespacial e o poder de uma nação. Apresentação oficial da AIAB. Abril, 2002.

ALBRECHT, K. Um modelo de inteligência organizacional. HSM Management. Barueri - SP, v. 3, n. 44 , p. 30-34, 2004.

AMATO NETO, J. Redes de cooperação produtiva e clusters regionais. São Paulo: Atlas, Fundação Vanzolini, 2000.

AMATO NETO, J. (Org.). Redes entre organizações: domínio do conhecimento e da eficácia operacional. São Paulo: Atlas, 2005.

ANGELONI, M. T. Organizações do conhecimento. São Paulo: Saraiva, 2002.

BENNIS, W. G. Organizações em mudança. São Paulo: Atlas, 1976.

$\mathrm{CHAl}, \mathrm{K}-\mathrm{H}$. Knowledge sharing and reuse international manufacturing networks. Institute for Manufacturing Engineering, University of Cambridge. Sep. 2000.

D`AVENI, R. D. A hipercompetição se aproxima. São Paulo: Makron Books, 2001.

DAVENPORT, T. O. Capital humano. São Paulo: Nobel, 2001.

DAY, G. A empresa orientada para o mercado. Porto Alegre: Bookman, 2001.

FIGUEIREDO, Paulo N. Aprendizagem Tecnológica e Inovação Industrial em Economias Emergentes: uma breve contribuição para o desenho e implementação de estudos empíricos e estratégias no Brasil. Revista Brasileira de Inovação. v. 3., n. 2., 2004.

FLEURY, A.; FLEURY, M. T. L. Estratégias empresariais e formação de competências. São Paulo: Atlas, 2000.

GRANGER, G-G. Por um conhecimento filosófico. Campinas: Papirus, 1989.

HAMEL, G; PRAHALAD, C. K. Competindo pelo futuro. Rio de Janeiro: Campus, 1995.

HARVEY, D. Condição pós-moderna. São Paulo: Loyola, 1996.

HITT, M. A.; IRELAND, R. D.; HOSKISSON, R. E. Administração estratégica. São Paulo: Pioneira Thomson Learning, 2002.

KANTER, R. M. Quando os gigantes aprendem a dançar. Rio de Janeiro: Campus, 1997.

MATTOS, J. R. L.; GUIMARÃES, L. S. Gestão da tecnologia e inovação: uma abordagem prática. São Paulo: Saraiva, 2005.

MAXIMIANO, A. C. A. Teoria geral da administração. São Paulo: Atlas, 2002.

MERTINS, K, HEISIG, P., VORBECK, J. Knowledge Management. concepts and best practices. 2a ed. Berlin. Spring-Verlag, 2003.

MORAIS, J. F. R. Ciência e perspectivas antropológicas de hoje. In: CARVALHO, M. C. M. C. (Org.). Construindo o saber. 13. ed. Campinas: Papirus, p. 87-96, 1989.
MORIN, E. Introdução ao pensamento complexo. Lisboa: Instituto Piaget, 1990.

NONAKA, I.; TAKEUCHI, H. Criação de conhecimento na empresa. Rio de Janeiro: Campus, 1997.

PORTER, M. Vantagem competitiva. Rio de Janeiro: Campus, 1989.

PRAHALAD, C. K. Reexame de Competências. HSM Management, n. 8, ano 2, mai-jul. 1998.

PRIGOGINE, I. O fim das certezas. São Paulo: UNESP, 1996.

SANTOS, I. C. Um modelo estruturado de gestão do conhecimento em indústrias de base tecnológica: um estudo de caso de uma empresa do setor aeronáutico. Tese de doutorado. São Paulo: Escola Politécnica da USP, 2004.

SBRAGIA, R. (Coord.); STAL, E.; CAMPANÁRIO, M. A.; ANDREASSI, T. Inovação: como vencer esse desafio empresarial. São Paulo: Clio Editora, 2006.

SCHEIN, E. Organizational culture and leadership. San Francisco: Jossey-Bass Inc., 1992.

SENGE, P. A quinta disciplina. São Paulo: Best Seller, 1990.

TIDD, J.; BESSANT, J.; PAVITT, K. Managing innovation: integrating, market and organization change. 3rd ed. West Sussex: John Wiley \& Sons Ltd. 2005.

\section{SOBRE OS AUTORES}

\section{Isabel Cristina dos Santos}

Universidade de Taubaté - UNITAU

End.: Rua Expedicionário Ernesto Pereira, Portão 3 - Centro - CEP 12030-320 - Taubaté, SP

Tel.: (12) 3625-4292

E-mail: isabelc.santos@terra.com.br

\section{João Amato Neto}

Departamento de Engenharia de Produção, Escola Politécnica da Universidade de São Paulo

Núcleo de pesquisa "Redes de Cooperação e Gestão do Conhecimento - REDECOOP"

End.: Av. Professor Almeida Prado, 128 - Trav. 2 - CEP 05508-900 - Cidade Universitária - São Paulo - SP

Tel.: (11) 3091-5363 r. 409

Fax: (11) 3091-5399

E-mail: amato@usp.br 